\title{
Controlled Synthesis of Manganese Dioxide Nanostructures via a Facile Hydrothermal Route
}

\author{
Suh Cem Pang, Suk Fun Chin, and Chian Ye Ling \\ Department of Chemistry, Faculty of Resource Science and Technology, Universiti Malaysia Sarawak, Sarawak, \\ 94300 Kota Samarahan, Malaysia \\ Correspondence should be addressed to Suh Cem Pang, suhcem@gmail.com
}

Received 4 October 2011; Accepted 5 December 2011

Academic Editor: Arava Leela Mohana Reddy

Copyright ( 92012 Suh Cem Pang et al. This is an open access article distributed under the Creative Commons Attribution License, which permits unrestricted use, distribution, and reproduction in any medium, provided the original work is properly cited.

Manganese dioxide nanostructures with controllable morphological structures and crystalline phases were synthesized via a facile hydrothermal route at low temperatures without using any templates or surfactants. Both the aging duration and aging temperatures were the main synthesis parameters used to influence and control the rate of morphological and structural evolution of $\mathrm{MnO}_{2}$ nanostructures. $\mathrm{MnO}_{2}$ nanostructures comprise of spherical nanoparticulate agglomerates and highly amorphous in nature were formed at lower temperature and/or short aging duration. In contrast, $\mathrm{MnO}_{2}$ nanostructures of sea-urchin-like and nanorods-like morphologies and nanocrystalline in nature were prepared at the combined higher aging temperatures and longer aging durations. These nanostructures underwent notable phase transformation from $\delta-\mathrm{MnO}_{2}$ to $\alpha-\mathrm{MnO}_{2}$ upon prolonged hydrothermal aging duration and exhibited accelerated rate of phase transformation at higher aging temperature.

\section{Introduction}

One-dimensional manganese dioxide $\left(\mathrm{MnO}_{2}\right)$ nanostructures such as nanorods, nanowires, and nanofibers have generated intense research interests over the past recent years due to their superior optical, electrical, catalytic, magnetic and electrochemical properties [1-3]. Such manganese dioxide nanostructures are of considerable importance in technological applications and have been intensively investigated as promising electrode materials in primary/secondary batteries and electrochemical capacitors due to their excellent electrochemical properties, low-cost, environmentally benign, and ease of preparation [4-7]. Various approaches have been used to fabricate manganese dioxide, such as self-reacting microemulsion [8], precipitation [9], room-temperature solid reaction [10], sonochemical [11], and hydrothermal methods [12]. The hydrothermal method is a powerful synthesis approach for synthesizing various forms of manganese oxides and affords various advantageous features including the use of mild synthesis conditions such as $\mathrm{pH}$ and temperature, and a wide range of precursors that can be used.

Various types of inorganic nanowires and nanorods have been synthesized with the aid of templates or catalysts. Templates are being used to confine the growth of crystals, while catalysts may act as energetically favorable sites for the adsorption of reactant molecules [13]. However, the introduction of templates or catalysts to a reaction system is often accompanied by drawbacks such as the need to prepare or select appropriate templates or catalysts. Besides, impurities in the final product may be difficult to be removed, thereby making the overall synthesis process more complicated and costly. As such, any synthetic method without the need to use any catalyst or template is more favorable for the preparation of low-dimensional nanostructures. Recently, a hydrothermal or solvothermal method has been employed to prepare one-dimensional nanoscaled materials, for example, $\alpha$ $\mathrm{MnO}_{2}$, without the use of templates or catalysts [14]. This method is superior to traditional methods since no specific and expensive equipment is required for synthesizing nanostructured materials at low temperatures. The hydrothermal preparation of manganese dioxides involved mainly redox reactions of $\mathrm{MnO}_{4}{ }^{-}$and/or $\mathrm{Mn}^{2+}$ or the phase transformation of granular manganese dioxide precursors [15]. A common approach for the synthesis of single-crystalline $\alpha-\mathrm{MnO}_{2}$ nanorods was based on the hydrothermal reaction of $\mathrm{MnSO}_{4}$ and $\mathrm{KMnO}_{4}$ [16]. DeGuzman et al. prepared fibrous $\alpha$ $\mathrm{MnO}_{2}$ through redox reactions between $\mathrm{KMnO}_{4}$ and $\mathrm{MnSO}_{4}$ 
[17]. However, some minor differences in the morphology of final products have been observed as specific reaction conditions were being altered slightly. Parameters such as temperature, time and capping molecules can influence the growth of nanocrystals under nonequilibrium kinetic growth conditions in the solution-based approach [18]. Henceforth, the controlled synthesis of manganese dioxide nanostructures with favorable surface morphology, phase structure, crystallinity, and high reproducibility remains a considerable challenge.

This paper reports the controlled synthesis of various $\mathrm{MnO}_{2}$ nanostructures via a facile and mild hydrothermal route without using any physical template and addition of any surfactant. Both $\delta-\mathrm{MnO}_{2}$ and $\alpha-\mathrm{MnO}_{2}$ nanostructures were synthesized based on the hydrothermal reaction of $\mathrm{MnSO}_{4}$ and $\mathrm{KMnO}_{4}$ in aqueous medium and at mild temperatures. Effects of hydrothermal synthesis conditions on the evolution of structural morphology and phase transformation of $\mathrm{MnO}_{2}$ nanostructures were investigated.

\section{Materials and Methods}

2.1. Synthesis of $\mathrm{MnO}_{2}$ Nanostructures. The synthesis of $\mathrm{MnO}_{2}$ nanoparticles was based on the method reported by Xiao et al. with some modifications [19]. $\mathrm{MnO}_{2}$ nanoparticles were synthesized by mixing aqueous solutions of $\mathrm{KMnO}_{4}$ and $\mathrm{MnSO}_{4}$ at ambient temperature and pressure, and the $\mathrm{pH}$ of solution mixture was adjusted to $\sim 1$ with concentrated $\mathrm{HNO}_{3}$. The aging temperatures were fixed at $25^{\circ} \mathrm{C}$ and $80^{\circ} \mathrm{C}$, whereas the aging duration varied between 1 hour and 24 hours. The reaction product was collected by filtration, washed, and then air-dried at room temperature.

2.2. Characterization of $\mathrm{MnO}_{2}$ Nanostructures. The surface and structural morphologies of $\mathrm{MnO}_{2}$ samples were studied by scanning electron microscope (SEM) (JEOL Model JSM 6390LA) and transmission electron microscope (TEM) (JEOL Model JEM-1230). For SEM imaging, all $\mathrm{MnO}_{2}$ samples were pre-coated with a thin platinum layer using an Ion Sputtering Device (JFC-1100 E) in order to reduce the inherent charging effect. As for TEM imaging, $\mathrm{MnO}_{2}$ samples were first being dispersed well in ultrapure water by ultrasonication. $1 \mu \mathrm{L}$ of the resulting dispersions were then drop-coated onto Formvar-covered copper grids and air-dried. The specific surface area and pore size distribution of $\mathrm{MnO}_{2}$ samples were determined using the nitrogen adsorption-desorption (BET) analyzer (Micrometrics ASAP $2010)$ at $77 \mathrm{~K}$. The phases of $\mathrm{MnO}_{2}$ samples synthesized at different aging durations and temperatures were studied using a X-ray diffractometer (XRD) (Scintag) with $\mathrm{Cu} \mathrm{K} \mathrm{K}_{\alpha}$ radiation source.

\section{Results and Discussion}

A facile and mild hydrothermal route was being used to synthesize $\mathrm{MnO}_{2}$ nanostructures without the use of any template or surfactant. Figures 1 and 2 show SEM micrographs of $\mathrm{MnO}_{2}$ samples after being aged for various durations at temperatures of $25^{\circ} \mathrm{C}$ and $80^{\circ} \mathrm{C}$, respectively. Both the aging duration and aging temperature were observed to have substantial effect on the shape and morphology of $\mathrm{MnO}_{2}$ nanostructures formed. At an aging temperature of $25^{\circ} \mathrm{C}$, spherical agglomerates of $\mathrm{MnO}_{2}$ nanoparticles were obtained at aging durations of between 0 hour and about 4 hours (Figure 1). In absence of surfactant, $\mathrm{MnO}_{2}$ nanoparticles showed high tendency to aggregate and formed spherical agglomerates of various sizes [20]. However, upon prolonged aging for 8 hours, nanorod-like structures began to develop on surfaces of individual $\mathrm{MnO}_{2}$ nanoparticles. Upon aging for more than 24 hours, well-defined nanorods had developed around these spherical $\mathrm{MnO}_{2}$ nanoparticles to form sea-urchin-like $\mathrm{MnO}_{2}$ nanostructures.

As shown in Figure 2, $\mathrm{MnO}_{2}$ samples synthesized initially at $80^{\circ} \mathrm{C}$ comprised of mainly spherical agglomerates. However, such spherical agglomerates were no longer discernible but large aggregates of nanorod-like structures were observed upon being aged for 4 hours at $80^{\circ} \mathrm{C}$. Well-defined and fully developed $\mathrm{MnO}_{2}$ nanorods were formed after being aged for extended durations of 8 and 24 hours at $80^{\circ} \mathrm{C}$, respectively. The aging temperature was found to play a crucial role in accelerating the rate of evolution of $\mathrm{MnO}_{2}$ nanostructures from spherical agglomerates to aggregates of well-defined nanorods. On the contrary, no $\mathrm{MnO}_{2}$ nanostructure was formed at the aging temperature of below $20^{\circ} \mathrm{C}$ even after being aged for a week. At the aging temperature of $25^{\circ} \mathrm{C}$, the rate of structural evolution was observed to be rather slow, with $\mathrm{MnO}_{2}$ nanostructures of sea-urchin-like shape formed only after being aged for 24 hours (Figure 1). However, at the elevated aging temperature of $80^{\circ} \mathrm{C}$, distinctive and well-defined $\mathrm{MnO}_{2}$ nanorod-like nanostructures were clearly discernable after being aged for 4 or more hours (Figure 2). A higher aging temperature appeared to favor the growth of one-dimensional (1D) $\mathrm{MnO}_{2}$ nanostructures which could be attributed to the accelerated rate of decomposition of $\mathrm{MnSO}_{4}$ to form $\mathrm{MnO}_{2}$ at elevated temperatures. These nanorod-like nanostructures continued to grow in length due to their anisotropic nature and eventually led to the formation of nanowires [21]. Henceforth, hydrothermal synthesis conditions could be controlled and optimized was for the synthesis of $\mathrm{MnO}_{2}$ nanostructures of desired morphology and crystalline phase.

Figure 3 shows TEM micrographs of $\mathrm{MnO}_{2}$ nanoparticles synthesized at various aging durations at aging temperatures of $25^{\circ} \mathrm{C}$. The evolution of nanorod-like nanostructures was observed to have initiated from the surfaces of $\mathrm{MnO}_{2}$ nanoparticles after being aged for 4 hours at $25^{\circ} \mathrm{C}$. More distinctive and defined nanorod-like nanostructures had evolved from spherical $\mathrm{MnO}_{2}$ nanoparticles after being aged for 8 hours. Long and well-defined nanorods were observed to have developed on $\mathrm{MnO}_{2}$ nanoparticles forming seaurchin-like nanostructures after being aged for 24 hours at $25^{\circ} \mathrm{C}$.

As shown in Figure 4, TEM micrographs depicted the rapid evolution of well-defined nanorods from individual spherical $\mathrm{MnO}_{2}$ nanoparticles at elevated aging temperature of $80^{\circ} \mathrm{C}$. Agglomerates of $\mathrm{MnO}_{2}$ nanoparticles were observed to have transformed rapidly into sea-urchin-like 


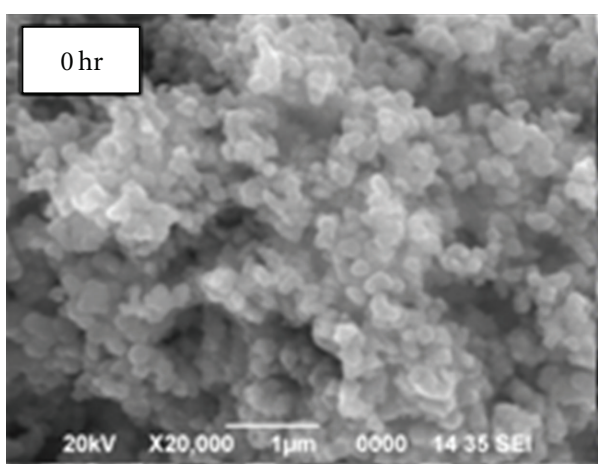

(a)

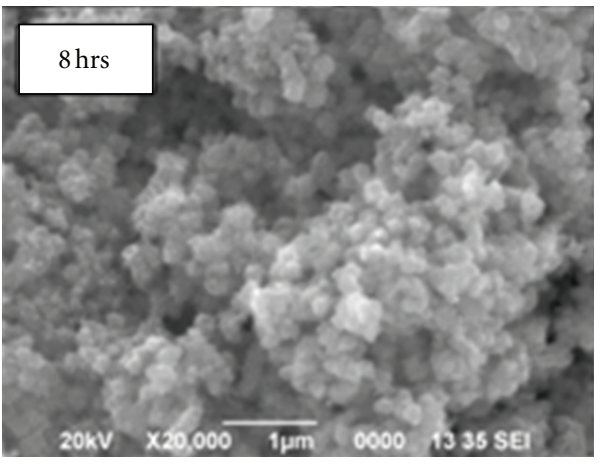

(c)

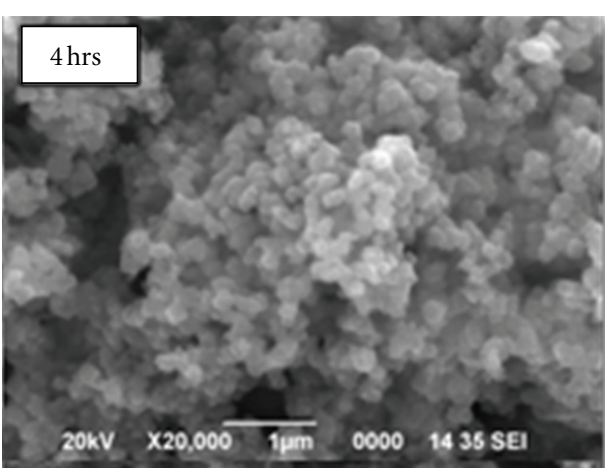

(b)

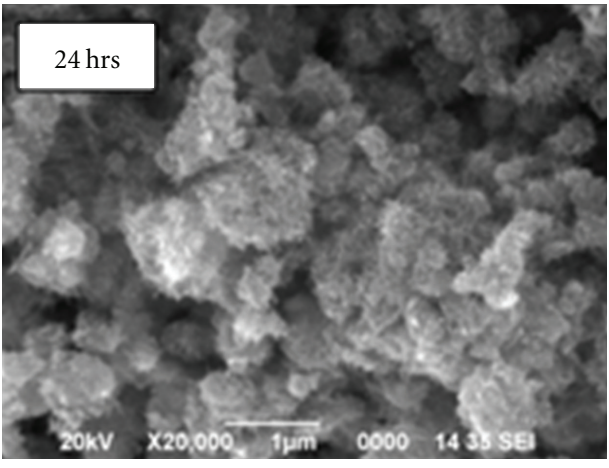

(d)

FIGURE 1: SEM micrographs of $\mathrm{MnO}_{2}$ samples synthesized at various aging durations at $25^{\circ} \mathrm{C}$.

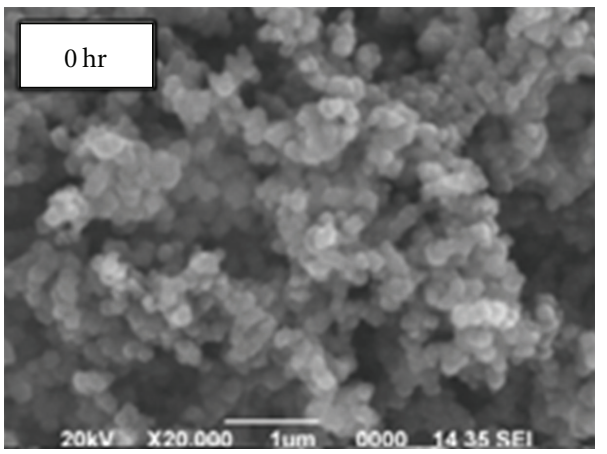

(a)

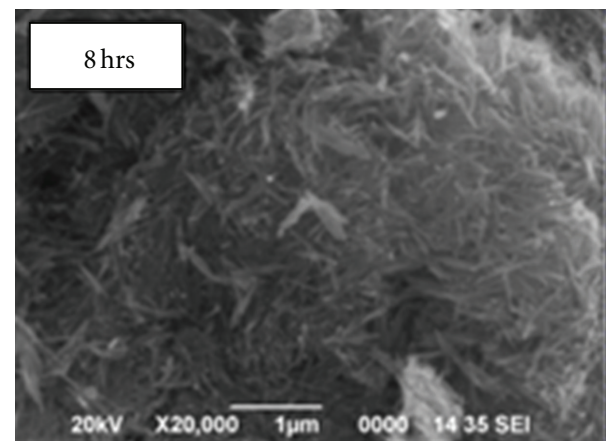

(c)

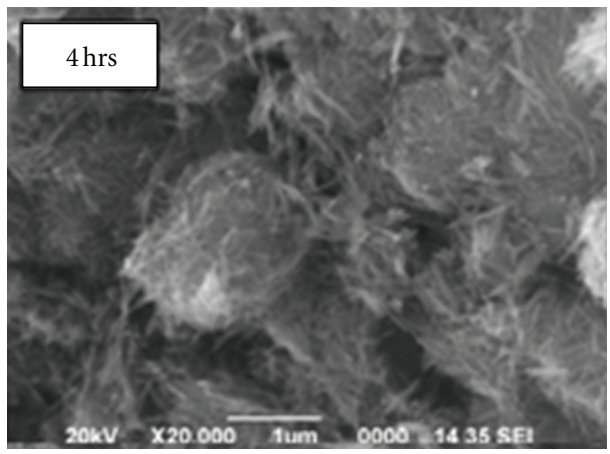

(b)

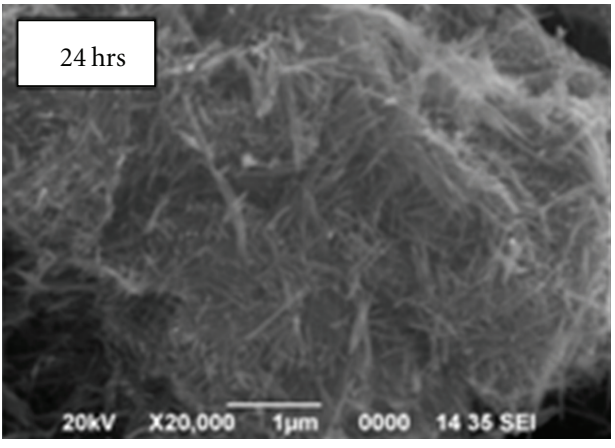

(d)

FIgURE 2: SEM micrographs of $\mathrm{MnO}_{2}$ samples synthesized at various aging durations at $80^{\circ} \mathrm{C}$. 


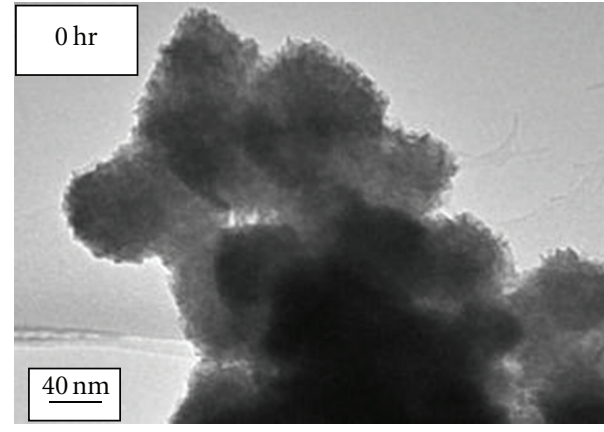

(a)

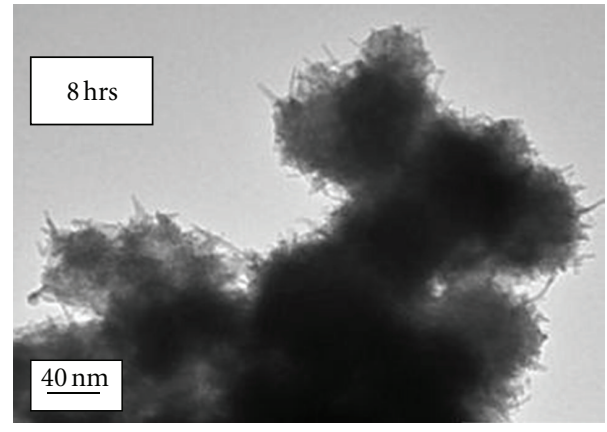

(c)

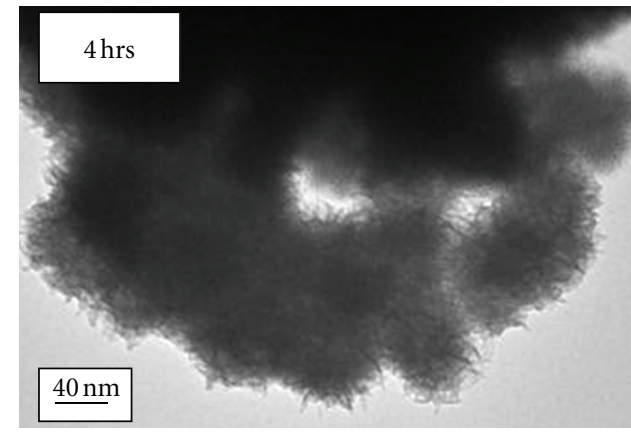

(b)

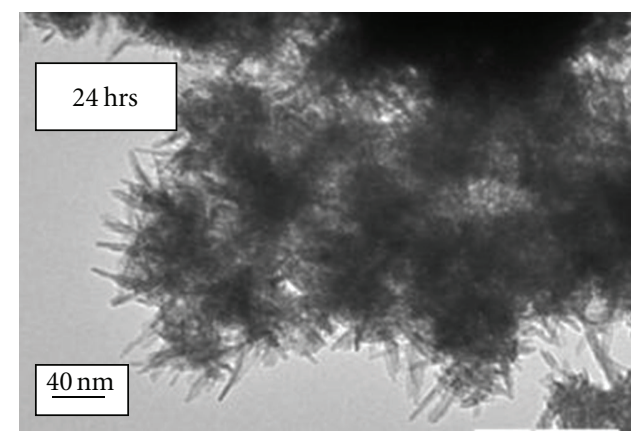

(d)

Figure 3: TEM micrographs of $\mathrm{MnO}_{2}$ samples synthesized at various aging durations at $25^{\circ} \mathrm{C}$.

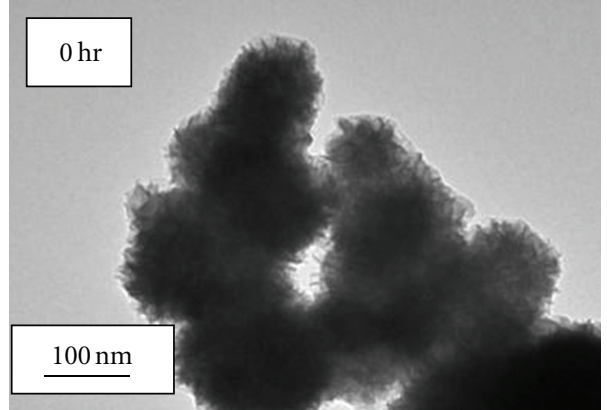

(a)

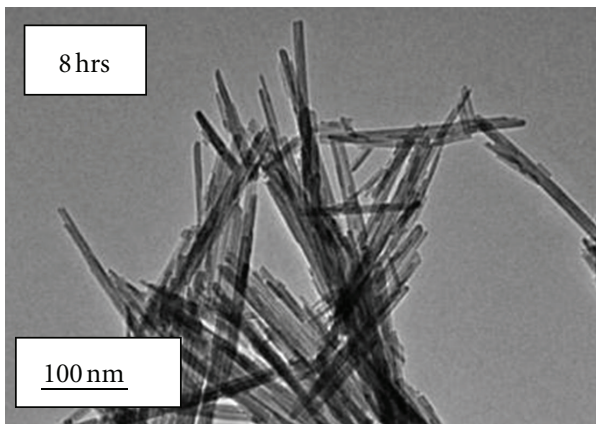

(c)

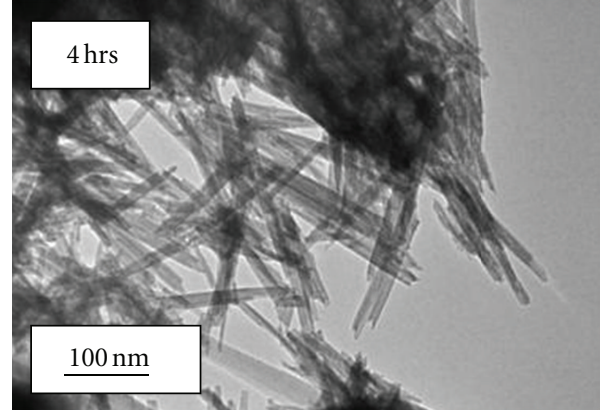

(b)

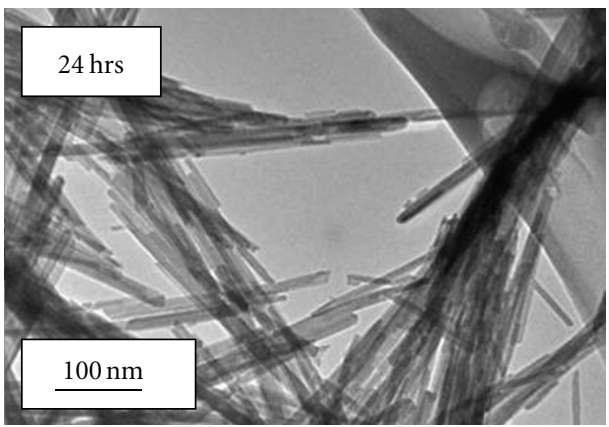

(d)

FIgURE 4: TEM micrographs of $\mathrm{MnO}_{2}$ samples synthesized at various aging durations at $80^{\circ} \mathrm{C}$. 


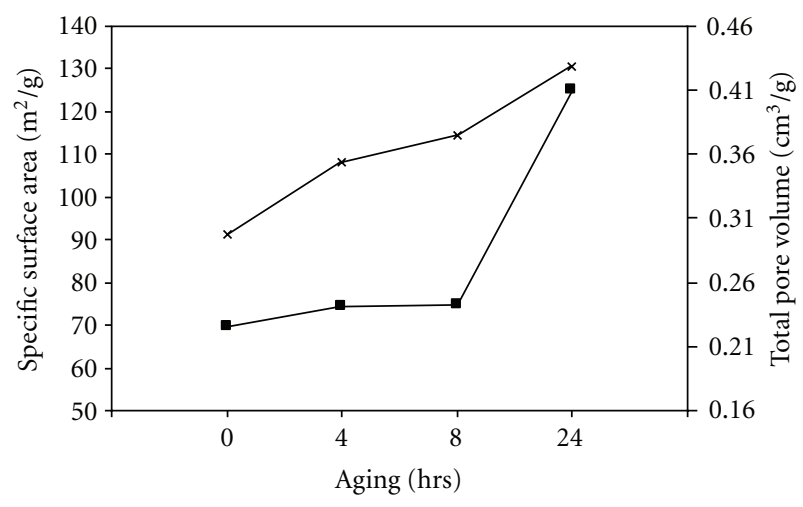

(a)

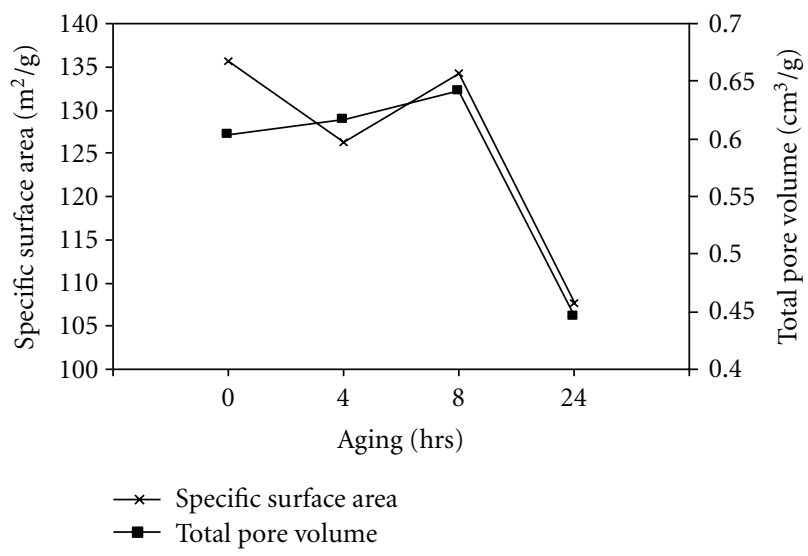

(b)

FIGURE 5: Effect of aging duration on the specific surface area and the total pore volume of $\mathrm{MnO}_{2}$ samples synthesized at (a) $25^{\circ} \mathrm{C}$ and (b) $80^{\circ} \mathrm{C}$.

nanostructures after being aged for 4 hours at $80^{\circ} \mathrm{C}$. All $\mathrm{MnO}_{2}$ nanoparticles were observed to have transformed completely into well-developed nanorods after being aged for 8 hours. No notable morphological changes of nanorods were observed after prolonged aging duration for up to 24 hours at $80^{\circ} \mathrm{C}$. The diameter and length of well-defined $\mathrm{MnO}_{2}$ nanorods ranged from 20 to $30 \mathrm{~nm}$ and 300 to $400 \mathrm{~nm}$, respectively.

The hydrothermal synthesis route used in the present study had been shown to be a facile and mild synthesis approach for the synthesis of manganese dioxide nanostructures of desired morphology through judicious control of both the aging temperature and aging duration. In this synthesis approach, neither catalyst was needed to provide energetically favorable sites for the absorption of reactant molecules nor template was needed to direct the growth of nanorods. The driving force for the growth of $\mathrm{MnO}_{2}$ nanorods during the synthesis process could be derived from the inherent crystal structure of $\mathrm{MnO}_{2}$ material and its chemical potential in solution [22]. Based on our experimental observations, the formation mechanisms of $\mathrm{MnO}_{2}$ nanostructures could entail the following processes. $\mathrm{MnO}_{2}$ nanoparticles were initially produced by the redox reaction between
$\mathrm{MnSO}_{4}$ and $\mathrm{KMnO}_{4}$. These $\mathrm{MnO}_{2}$ nanoparticles would subsequently aggregate to form spherical agglomerates due to their high surface energies. During prolonged aging duration, $\mathrm{MnO}_{2}$ nanoparticles would gradually transform into nanorods under the specific aging conditions. The gradual transformation of $\mathrm{MnO}_{2}$ nanoparticles into nanorods could be attributed to their one-dimensional growth and anisotropic nature. Such processes obey the well-known "Ostwald Ripening" process, in which larger nanorods grow at the expense smaller ones because of differences in their surface energies. Similar formation mechanism of $\mathrm{MnO}_{2}$ nanorods had been reported byTang et al. with single-crystalline $\alpha-\mathrm{MnO}_{2}$ nanorods being successfully synthesized via a facile hydrothermal approach without any template and surfactant [23].

Figure 5 shows the effect of aging duration on the specific surface area and total pore volume of $\mathrm{MnO}_{2}$ nanostructures synthesized at different aging temperatures of $25^{\circ} \mathrm{C}$ and $80^{\circ} \mathrm{C}$. For $\mathrm{MnO}_{2}$ samples synthesized at aging temperature of $25^{\circ} \mathrm{C}$, both specific surface area and total pore volume were observed to increase with increasing aging durations. The specific surface area and total pore volume of $\mathrm{MnO}_{2}$ samples increased from $91.1 \mathrm{~m}^{2} / \mathrm{g}$ and $0.225 \mathrm{~cm}^{3} / \mathrm{g}$ as prepared (or without aging) to $130.5 \mathrm{~m}^{2} / \mathrm{g}$ and $0.410 \mathrm{~cm}^{3} / \mathrm{g}$, respectively, after being aged for 24 hours. Such increases could be attributed to microstructural changes associated with the gradual transformation of tightly packed nanoparticles into nanorod-like structures during aging. $\mathrm{MnO}_{2}$ nanostructures of evolving nanorods should possess higher porosity as indicated by the increasing specific surface area and total pore volume with longer aging durations. In contrast, $\mathrm{MnO}_{2}$ samples synthesized at aging durations between 0 and 8 hours at $80^{\circ} \mathrm{C}$ showed substantially higher values of specific surface area and total pore volume which were comparable or even higher than $\mathrm{MnO}_{2}$ samples synthesized after being aged for 24 hours at $25^{\circ} \mathrm{C}$ (Figure 5). However, there was a notable decrease in both specific surface area and total pore volume for samples synthesized after being aged for 24 hours (Figure 5(b)) which could be due to aggregation and realignment of fully developed nanorods. These results showed that a substantially higher rate of transformation from spherical nanoparticles to nanorods occurred at elevated aging temperature, with complete transformation being achieved within 1 hour of aging duration at $80^{\circ} \mathrm{C}$ as compared to more than 24 hours at $25^{\circ} \mathrm{C}$.

Figure 6 shows X-ray diffractographs of $\mathrm{MnO}_{2}$ samples as prepared and after being aged for 24 hours at $25^{\circ} \mathrm{C}$ and $80^{\circ} \mathrm{C}$. Both types of as-prepared $\mathrm{MnO}_{2}$ samples without any post synthesis aging showed similar broad diffraction peaks which can be indexed to $\delta$ - $\mathrm{MnO}_{2}$ phase albeit with low degree of crystallinity. The absence of other manganese dioxide diffraction peaks indicated the high purity of these as-prepared $\delta$ - $\mathrm{MnO}_{2}$ samples. $\delta$ - $\mathrm{MnO}_{2}$ samples synthesized at $25^{\circ} \mathrm{C}$ were observed to have only partially converted to $\alpha$ $\mathrm{MnO}_{2}$ phase as indicated by the 211 peak but have remained mostly amorphous in nature after being aged for 24 hours (Figure 6(a)). In contrast, samples of highly crystalline $\alpha$ $\mathrm{MnO}_{2}$ phase were obtained after being aged for 24 hours 


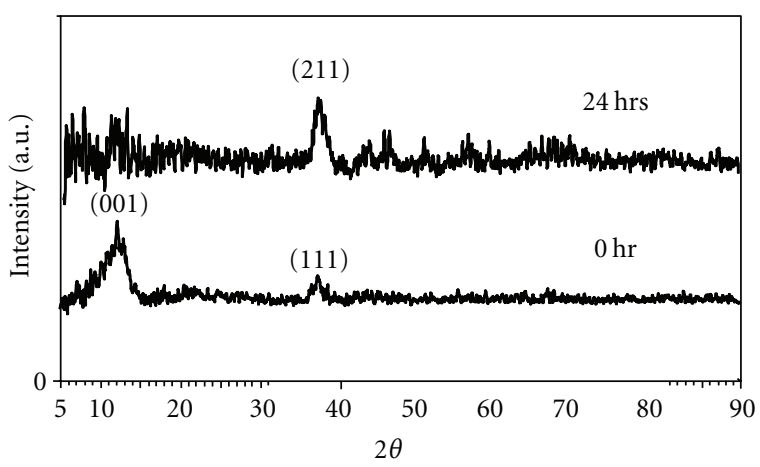

(a)

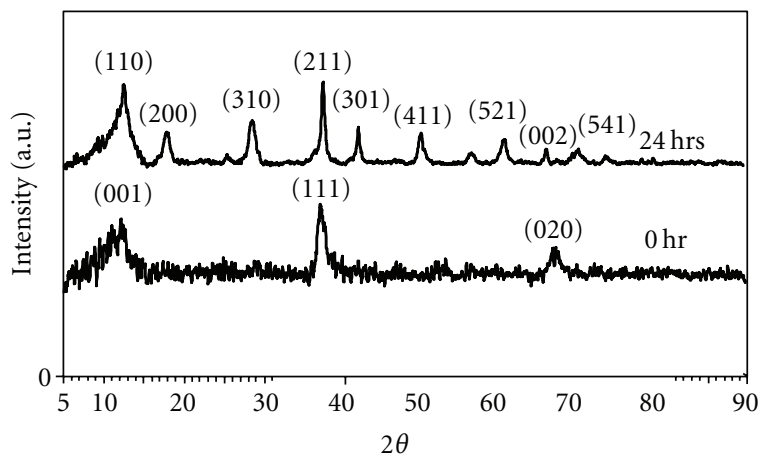

(b)

Figure 6: XRD diffractographs of $\mathrm{MnO}_{2}$ samples synthesized at (a) $25^{\circ} \mathrm{C}$ and (b) $80^{\circ} \mathrm{C}$ with different aging duration.

at a higher aging temperature of $80^{\circ} \mathrm{C}$. The presence of well-defined and sharp characteristic diffraction peaks of $\alpha$ $\mathrm{MnO}_{2}$ phase showed a complete phase transformation of $\delta$ $\mathrm{MnO}_{2}$ into $\alpha-\mathrm{MnO}_{2}$ phase upon aging at $80^{\circ} \mathrm{C}$ for 24 hours (Figure 6(b)). Such phase transformation could be associated with the simultaneous morphological transformation from spherical nanoparticles to nanorods during prolonged aging at $80^{\circ} \mathrm{C}$. These results indicated that the rates of phase and morphological transformation were temperature dependent, with accelerated rate occurred at elevated aging temperature. Our findings concurred with observations reported by other researchers that a higher aging temperature would promote more rapid phase transformation of $\mathrm{MnO}_{2}$ samples [24, 25]. The phase transformation from $\delta-\mathrm{MnO}_{2}$ to $\alpha-\mathrm{MnO}_{2}$ could also be attributed to the stability of the polymorphs of $\mathrm{MnO}_{2}$. Since $\delta-\mathrm{MnO}_{2}$ is less stable than $\alpha-\mathrm{MnO}_{2}$ and $\beta$ $\mathrm{MnO}_{2}$, it will be transformed into $\alpha-\mathrm{MnO}_{2}$ or $\beta-\mathrm{MnO}_{2}$ with increasing temperature [26]. However, due to the mild reaction conditions used in the present study, the $\beta-\mathrm{MnO}_{2}$ phase could not be formed. These above results indicated that both the morphological structure and crystalline phase of $\mathrm{MnO}_{2}$ samples could be modulated by varying the hydrothermal aging duration and temperatures.

\section{Conclusion}

In conclusion, $\mathrm{MnO}_{2}$ nanostructures of spherical nanoparticulate agglomerates could be synthesized and transformed into nanostructures of sea-urchin-like or agglomerates of nanorods by a facile and mild hydrothermal route without the use of any templates or catalyst. $\mathrm{MnO}_{2}$ nanostructures underwent accelerated rate of transformation from $\delta-\mathrm{MnO}_{2}$ to $\alpha-\mathrm{MnO}_{2}$ phase and associated morphological changes from spherical nanoparticles to nanorods at elevated aging temperature. Both the morphological structure and crystalline phase of the $\mathrm{MnO}_{2}$ nanostructures could therefore be modulated by varying the hydrothermal aging duration and temperatures.

\section{Acknowledgment}

This work was supported in part by the Universiti Malaysia Sarawak under the special fundamental Research Grant 01(K03)/557/2005(56).

\section{References}

[1] V. Subramanian, H. Zhu, R. Vajtai, P. M. Ajayan, and B. Wei, "Hydrothermal synthesis and pseudocapacitance properties of $\mathrm{MnO}_{2}$ nanostructures," Journal of Physical Chemistry B, vol. 109, no. 43, pp. 20207-20214, 2005.

[2] S. F. Chin, S. C. Pang, and M. A. Anderson, "Self-assembled manganese dioxide nanowires as electrode materials for electrochemical capacitors," Materials Letters, vol. 64, no. 24, pp. 2670-2672, 2010.

[3] Y. S. Ding, X. F. Shen, S. Gomez, H. Luo, M. Aindow, and S. L. Suib, "Hydrothermal growth of manganese dioxide into three-dimensional hierarchical nanoarchitectures," Advanced Functional Materials, vol. 16, no. 4, pp. 549-555, 2006.

[4] S. C. Pang and M. A. Anderson, "Novel electrode materials for electrochemical capacitors: Part II. Material characterization of sol-gel-derived and electrodeposited manganese dioxide thin films," Journal of Materials Research, vol. 15, no. 10, pp. 2096-2106, 2000.

[5] S. C. Pang, M. A. Anderson, and T. W. Chapman, "Novel electrode materials for thin-film ultracapacitors: comparison of electrochemical properties of sol-gel-derived and electrodeposited manganese dioxide," Journal of the Electrochemical Society, vol. 147, no. 2, pp. 444-450, 2000.

[6] S. F. Chin, S. C. Pang, and M. A. Anderson, "Material and electrochemical characterization of tetrapropylammonium manganese oxide thin films as novel electrode materials for electrochemical capacitors," Journal of the Electrochemical Society, vol. 149, no. 4, pp. A379-A384, 2002.

[7] S. F. Chin and S. C. Pang, "Tetrapropylammonium-manganese oxide/polypyrrole hybrid nanocomposite thin films as novel electrode materials for supercapacitors," Materials Chemistry and Physics, vol. 124, no. 1, pp. 29-32, 2010.

[8] C. Xu, B. Li, H. Du, F. Kang, and Y. Zeng, "Electrochemical properties of nanosized hydrous manganese dioxide synthesized by a self-reacting microemulsion method," Journal of Power Sources, vol. 180, no. 1, pp. 664-670, 2008.

[9] V. Subramanian, H. Zhu, and B. Wei, "Alcohol-assisted room temperature synthesis of different nanostructured manganese oxides and their pseudocapacitance properties in neutral electrolyte," Chemical Physics Letters, vol. 453, no. 4-6, pp. 242249, 2008.

[10] A. Yuan, X. Wang, Y. Wang, and J. Hu, "Textural and capacitive characteristics of $\mathrm{MnO}_{2}$ nanocrystals derived from a novel 
solid-reaction route," Electrochimica Acta, vol. 54, no. 3, pp. 1021-1026, 2009.

[11] A. Zolfaghari, F. Ataherian, M. Ghaemi, and A. Gholami, "Capacitive behavior of nanostructured $\mathrm{MnO}_{2}$ prepared by sonochemistry method," Electrochimica Acta, vol. 52, no. 8, pp. 2806-2814, 2007.

[12] D. Yan, P. Yan, S. Cheng et al., "Fabrication, in-depth characterization, and formation mechanism of crystalline porous birnessite $\mathrm{MnO}_{2}$ film with amorphous bottom layers by hydrothermal method," Crystal Growth and Design, vol. 9, no. 1, pp. 218-222, 2009.

[13] L. Zhang, Z. H. Liu, X. Tang, J. Wang, and K. Ooi, "Synthesis and characterization of $\beta-\mathrm{MnO}_{2}$ single crystals with novel tetragonous morphology," Materials Research Bulletin, vol. 42, no. 8, pp. 1432-1439, 2007.

[14] X. Wang and Y. Li, "Rational synthesis of $\alpha-\mathrm{MnO}_{2}$ single-crystal nanorods," Chemical Communications, no. 7, pp. 764-765, 2002.

[15] X. Zhang, W. Yang, J. Yang, and D. G. Evans, "Synthesis and characterization of $\alpha-\mathrm{MnO}_{2}$ nanowires: self-assembly and phase transformation to $\beta-\mathrm{MnO}_{2}$ microcrystals," Journal of Crystal Growth, vol. 310, no. 3, pp. 716-722, 2008.

[16] X. Wang and Y. Li, "Synthesis and formation mechanism of manganese dioxide nanowires/nanorods," Chemistry - A European Journal, vol. 9, no. 1, pp. 300-306, 2003.

[17] R. N. DeGuzman, Y. F. Shen, E. J. Neth et al., "Synthesis and characterization of Octahedral Molecular Sieves (OMS-2) having the hollandite structure," Chemistry of Materials, vol. 6, no. 6, pp. 815-821, 1994.

[18] J. Wu, H. Zhang, X. Ma et al., "Synthesis and characterization of single crystalline $\mathrm{MnOOH}$ and $\mathrm{MnO}_{2}$ nanorods by means of the hydrothermal process assisted with CTAB," Materials Letters, vol. 60, no. 29-30, pp. 3895-3898, 2006.

[19] T. D. Xiao, P. R. Strutt, M. Benaissa, H. Chen, and B. H. Kear, "Synthesis of high active-site density nanofibrous $\mathrm{MnO}_{2}$ base materials with enhanced permeabilities," Nanostructured Materials, vol. 10, no. 6, pp. 1051-1061, 1998.

[20] R. Jiang, T. Huang, J. Liu, J. Zhuang, and A. Yu, "A novel method to prepare nanostructured manganese dioxide and its electrochemical properties as a supercapacitor electrode," Electrochimica Acta, vol. 54, no. 11, pp. 3047-3052, 2009.

[21] Y. Dong, H. Yang, K. He, S. Song, and A. Zhang, " $\beta-\mathrm{MnO}_{2}$ nanowires: a novel ozonation catalyst for water treatment," $A p$ plied Catalysis B: Environmental, vol. 85, no. 3-4, pp. 155-161, 2009.

[22] Z. Y. Yuan, Z. Zhang, G. Du, T. Z. Ren, and B. L. Su, "A simple method to synthesise single-crystalline manganese oxide nanowires," Chemical Physics Letters, vol. 378, no. 3-4, pp. 349-353, 2003.

[23] N. Tang, X. Tian, C. Yang, Z. Pi, and Q. Han, "Facile synthesis of $\alpha-\mathrm{MnO}_{2}$ nanorods for high-performance alkaline batteries," Journal of Physics and Chemistry of Solids, vol. 71, no. 3, pp. 258-262, 2010.

[24] X. Wang and Y. Li, "Synthesis and formation mechanism of manganese dioxide nanowires/nanorods," Chemistry-A European Journal, vol. 9, no. 1, pp. 300-306, 2003.

[25] Y. Yang and C. Huang, "Effect of synthetical conditions, morphology, and crystallographic structure of $\mathrm{MnO}_{2}$ on its electrochemical behavior," Journal of Solid State Electrochemistry, vol. 14, no. 7, pp. 1293-1301, 2010.

[26] P. M. de Wolff, "Interpretation of some $\gamma-\mathrm{MnO}_{2}$ diffraction patterns," Acta Crystallograhica, vol. 12, pp. 341-345, 1959. 

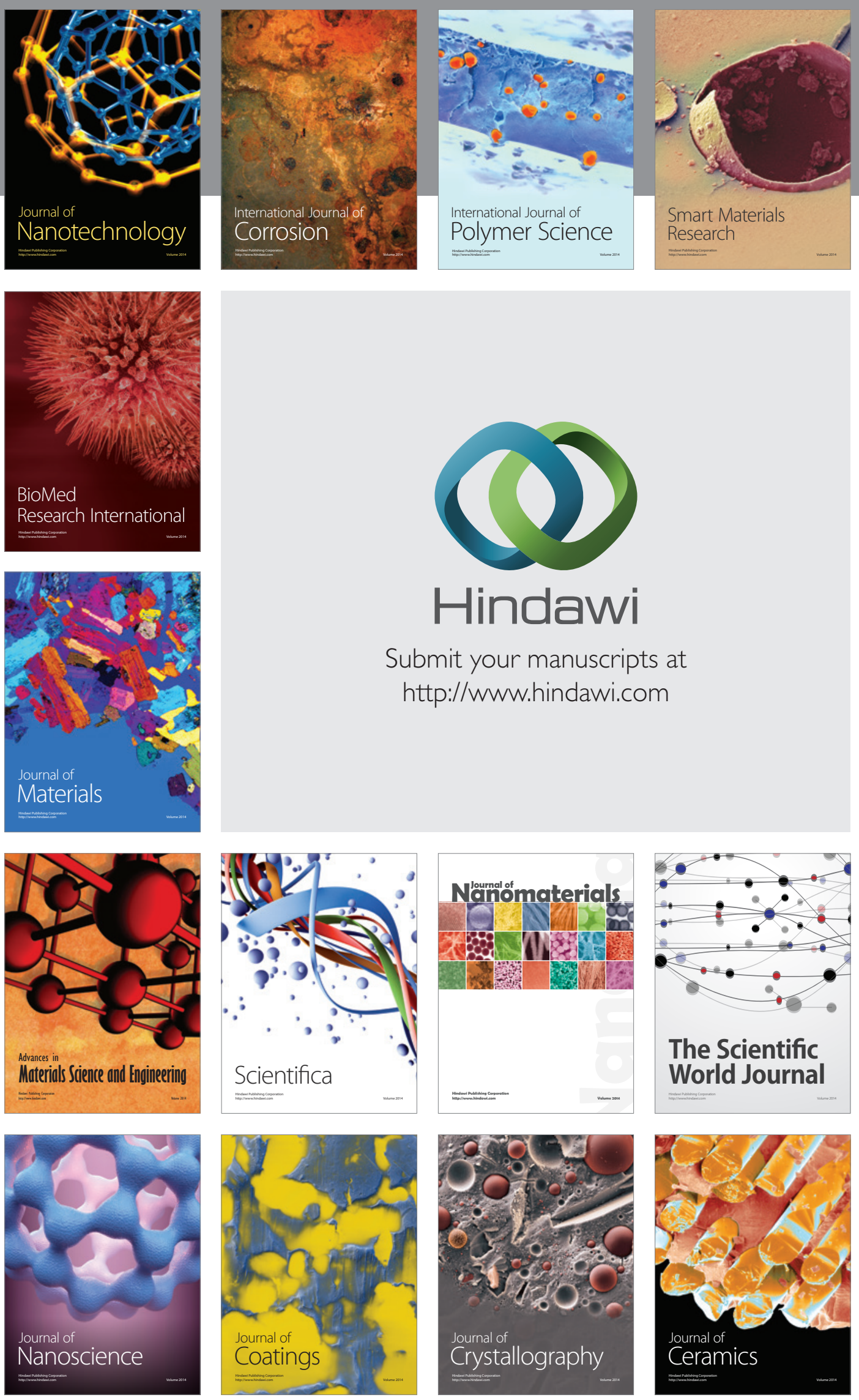

The Scientific World Journal

Submit your manuscripts at

http://www.hindawi.com

\section{World Journal}

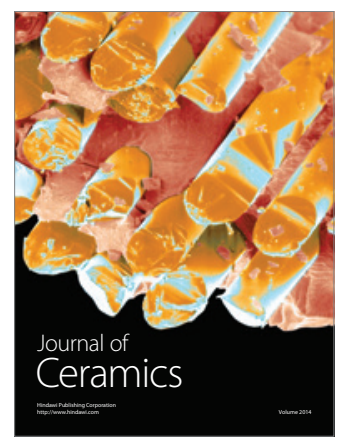

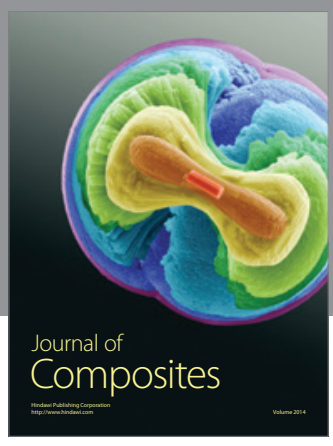
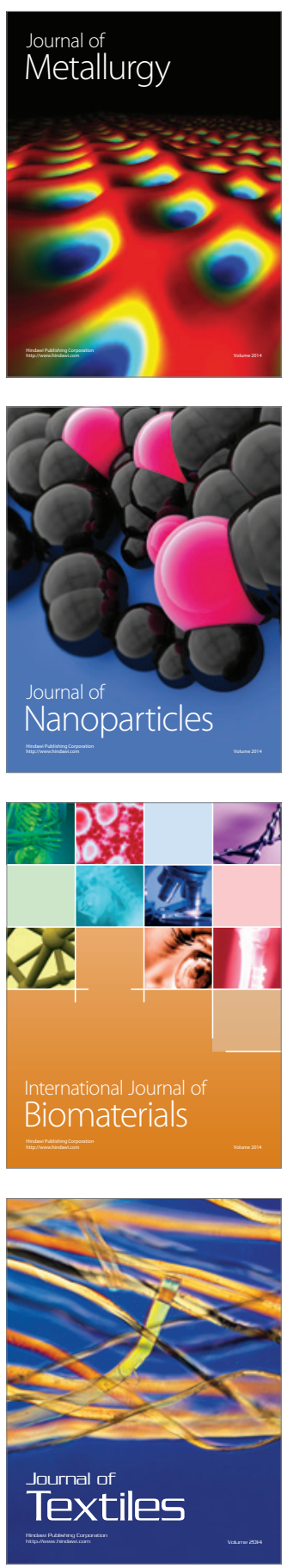